\title{
General Model for Representing Variable Speed Wind Turbines in Power System Dynamics Simulations
}

\author{
J. G. Slootweg, Member, IEEE, S. W. H. de Haan, Member, IEEE, H. Polinder, Member, IEEE, and \\ W. L. Kling, Member, IEEE
}

\begin{abstract}
A tendency to erect ever more wind turbines can be observed in order to reduce the environmental consequences of electric power generation. As a result of this, in the near future, wind turbines may start to influence the behavior of electric power systems by interacting with conventional generation and loads. Therefore, wind turbine models that can be integrated into power system simulation software are needed.

In this contribution, a model that can be used to represent all types of variable speed wind turbines in power system dynamics simulations is presented. First, the modeling approach is commented upon and models of the subsystems of which a variable speed wind turbine consists are discussed. Then, some results obtained after incorporation of the model in PSS/E, a widely used power system dynamics simulation software package, are presented and compared with measurements.
\end{abstract}

Index Terms-Grid integration, modeling, power system dynamics, PSS/E, simulation, variable speed wind turbine.

\section{INTRODUCTION}

A S A RESULT of increasing environmental concern, the impact of conventional electricity generation on the environment is being minimized and efforts are made to generate electricity from renewable sources. The main advantages of electricity generation from renewable sources are the absence of harmful emissions and the infinite availability of the prime mover that is converted into electricity. One way of generating electricity from renewable sources is to use wind turbines that convert the energy contained in flowing air into electricity. Up to this moment, the amount of wind power integrated into large-scale electric power systems only covers a small part of the total power system load. The rest of the power system load is for the largest part covered by conventional thermal, nuclear, and hydropower plants.

Wind turbines mostly do not take part in voltage and frequency control and if a disturbance occurs, the wind turbines are disconnected and reconnected when normal operation has been resumed. Thus, notwithstanding the presence of wind turbines, frequency and voltage are maintained by controlling the large power plants as would have been the case without any wind turbines present.

This is possible, as long as wind power penetration is still low. However, a tendency to increase the amount of electricity gen-

Manuscript received April 26, 2001; revised May 17, 2002. This work was supported by the Dutch Organization for Scientific Research (NWO).

The authors are with Faculty of Information Technology and Systems, Delft University of Technology, 2600 GA Delft, The Netherlands (e-mail: j.g.slootweg@its.tudelft.nl).

Digital Object Identifier 10.1109/TPWRS.2002.807113 erated from wind can be observed. Therefore, the penetration of wind turbines in electric power systems will increase and they may begin to influence overall power system behavior, making it impossible to run a power system by only controlling conventional large-scale power plants. It is therefore important to study the behavior of wind turbines in an electric power system and their interaction with other generation equipment and with loads.

In this paper, a general model for representation of variablespeed wind turbines in power system dynamics simulations is presented. The model has been developed to facilitate the investigation of the impact of large amounts of wind turbines on the behavior of an electric power system. Power systems simulation software is used to study this subject. Therefore, the level of detail of the model derived here is similar to the level of detail of models of other generation equipment in power systems simulation software. This enables the integration of the model in these programs as is shown by simulation results.

The paper is organized as follows. First, the modeling approach is commented upon and models of the subsystems of which a variable speed consists are discussed. Then, simulation results obtained after integration of the derived variablespeed wind turbine model in the power system dynamics simulation software package PSS/E are presented and compared with measurements.

\section{MODEL REQUiREMENTS}

The goal of the work is to develop a general model to represent the two most important actual variable-speed wind turbine concepts in power system dynamics simulations. In the first concept, variable-speed operation is enabled through the use of a doubly fed induction generator with a back-to-back voltage source converter feeding the rotor winding. In the second concept, a direct drive synchronous generator is used, which is grid coupled through a diode rectifier and voltage source converter or through a back-to-back voltage source converter. The derived model can also be used to represent the variable-speed wind turbine concept of a squirrel cage induction generator, grid coupled through a back-to-back voltage source converter, which is, however, not used very much in practice and will therefore not be paid further attention to. Detailed descriptions of these concepts can be found in textbooks on wind energy, for example, [1].

Keeping in mind that our goal is to derive a model that can be used in power system dynamics simulations, it should be possible to easily integrate the developed model into power system 
dynamics simulation software packages. To make this possible indeed, a number of requirements have to be posed on the model, namely

- The wind turbine model should have a level of detail similar to the models of the other system components (i.e., only the subsystems that determine the behavior in the frequency range of interest should be incorporated in the model).

- The wind turbine model should be characterized by a minimum number of parameters.

- Integration of the wind turbine model should not lead to the need for a smaller simulation time step.

- The wind turbine model should only contain fundamental harmonic components of current and voltage, because transients and harmonics are not taken into account in power system dynamics simulations.

The last requirement leads to a decrease in computation time, because the number of differential equations is substantially reduced and because a larger time step can be used due to the neglect of small time constants [2], [3].

\section{SubSYSTEM Models}

\section{A. Subsystems}

In this section, the various subsystems of a variable-speed wind turbine will be modeled, namely

- wind speed model for generating a wind speed signal that can be applied to the rotor;

- rotor model for converting the kinetic energy contained in the wind into mechanical power that can be applied to the generator;

- model of the generator and the converter, converting mechanical power into electric power and determining the rotor speed;

- rotor speed controller for deriving a power set point from the rotor speed versus generator power control characteristic, based on the actual rotor speed;

- pitch angle controller for changing the blade pitch above nominal wind speed preventing the rotor speed from becoming too high;

- voltage controller for keeping the terminal voltage near its reference value;

- protection system for limiting the converter current and for switching off the wind turbine when terminal voltage or grid frequency deviation exceed a specified value for a given time.

In Fig. 1, the above subsystems and the way they are connected is depicted.

\section{B. Wind Speed Model}

The wind speed model consists of a source that generates a wind speed signal to be applied to the wind turbine. The wind speed signal consists of four components, namely the mean wind speed; a wind speed ramp, which is a steady increase in the mean wind speed; a wind gust; and turbulence. The eventual wind speed to be applied to the wind turbine is the sum of these four components [4], [5].

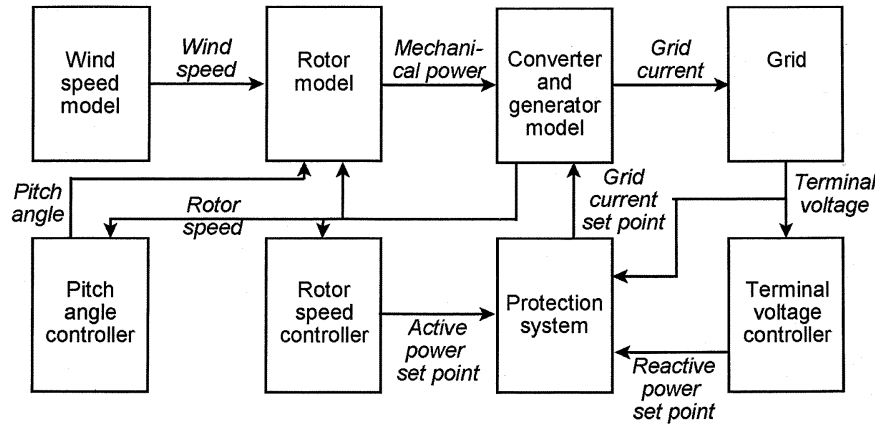

Fig. 1. Subsystems of which the variable speed wind turbine model consists and their interactions.

TABLE I

VALUES OF ROUGHNESS LENGTH $z_{0}$ FOR VARIOUS LANDSCAPE TYPES [9], [10]

\begin{tabular}{l|l}
\hline Landscape type & Roughness length $\mathbf{z}_{\mathbf{0}}[\mathbf{m}]$ \\
\hline Open sea, Sand & $1 \mathrm{e}-4-1 \mathrm{e}-3$ \\
\hline Snow surface & $1 \mathrm{e}-3-5 \mathrm{e}-3$ \\
\hline Mown grass, Steppe & $1 \mathrm{e}-3-1 \mathrm{e}-2$ \\
\hline Long grass, Rocky ground & $0.04-0.1$ \\
\hline Forests, Cities, Hilly areas & $1-5$ \\
\hline
\end{tabular}

Below the nominal wind speed, the initial wind speed is computed from the power delivered by the wind turbine, as set in the load flow used to initialize the dynamic simulation. Above the nominal wind speed, an initial mean wind speed value has to be given, because above the nominal wind speed, there is no unique relation between wind speed and generated power [6].

The wind speed ramp is characterized by three parameters, namely:

- amplitude of the wind speed $\operatorname{ramp} A_{r}[\mathrm{~m} / \mathrm{s}]$;

- starting time of the wind speed $\operatorname{ramp} T_{s r}[\mathrm{~s}]$;

- end time of the wind speed ramp $T_{e r}[\mathrm{~s}]$.

The wind speed gust is characterized by three parameters as well, namely

- amplitude of the wind speed gust $A_{g}[\mathrm{~m} / \mathrm{s}]$;

- starting time of the wind speed gust $T_{s g}$ [s];

- end time of the wind speed gust $T_{e g}[\mathrm{~s}]$.

The wind gust is modeled using the following equation [4], [5]:

$$
\begin{aligned}
t & <T_{s g}: v_{w g}=0 \\
T_{s g} & \leq t \leq T_{e g}: v_{w g}=A_{g}\left[1-\cos \left(2 \pi\left(t / D_{g}-T_{s g} / D_{g}\right)\right)\right] \\
T_{e g} & <t: v_{w g}=0
\end{aligned}
$$

where $D_{g}$ is the duration of the gust [s], which equals $T_{e g}-T_{s g}$.

The turbulence has been modeled as a stationary process, using the following equation for the turbulence spectral density [7]:

$$
S(f)=\frac{\frac{1}{\ln \left(h / z_{0}\right)^{2}} \cdot l \cdot v_{w}}{\left(1+1.5 \frac{f \cdot l}{v_{w}}\right)^{5 / 3}}
$$

where $f$ is the frequency $[\mathrm{Hz}] ; h$ is the height at which the wind speed signal is of interest [m], which normally equals the height of the wind turbine shaft; $v_{w}$ is the mean wind speed [m/s]; $l$ is the turbulence length scale [m] which equals $20 \cdot h$ if $h$ is less 
than $30 \mathrm{~m}$ and 600 if $h$ is more than $30 \mathrm{~m}$; and $z_{0}$ is the roughness length $[\mathrm{m}]$.

The roughness length depends on the structure of the landscape surrounding the wind turbine. In Table I, the values of $z_{0}$ for various landscape types are given. Through the parameter $z_{0}$, the dependence of the turbulence intensity on the landscape in which the studied wind turbine is erected is taken into account.

In power system dynamics simulations, a signal in the time domain instead of in the frequency domain is needed. The method used here to derive a time-domain signal from a power spectral density is described in [8] and used in [4] and [5].

The wind turbine model offers the possibility to change the values of all characteristics of the wind speed signal to be applied, apart from the starting value of the mean wind speed when the wind turbine delivers less than nominal power. This value is calculated on the basis of the power generated by the wind turbine in the initial load flow.

\section{Modeling of the Rotor}

The wind turbine rotor, that extracts the energy from the wind and converts it into mechanical power is a complex aerodynamic system. For state-of-the-art modeling of the rotor, blade element theory must be used [1]. Modeling the rotor using blade element theory has, however, a number of drawbacks.

- Instead of only one wind speed signal, an array of wind speed signals has to be applied.

- Detailed information about the rotor geometry should be available.

- Computations become complicated and lengthy.

To solve these problems, a simplified way of modeling the wind turbine rotor is normally used when the electrical behavior of the system is the main point of interest. An algebraic relation between wind speed and mechanical power extracted is assumed, which is described by the following equation:

$$
P_{w}=\frac{1}{2} \rho A_{r} c_{p}(\lambda, \theta) v_{w}^{3}
$$

where $P_{w}$ is the power extracted from the wind [W]; $\rho$ is the air density $\left[\mathrm{kg} / \mathrm{m}^{3}\right] ; c_{p}$ is the performance coefficient or power coefficient; $\lambda$ is the tip speed ratio; $v_{t} / v_{w}$ is the ratio between blade tip speed $v_{t}[\mathrm{~m} / \mathrm{s}]$ and wind speed at hub height upstream the rotor $v_{w}[\mathrm{~m} / \mathrm{s}] ; \theta$ is the pitch angle of rotor blades [deg]; and $A_{r}$ is the area covered by the rotor $\left[\mathrm{m}^{2}\right]$.

Numerical approximations have been developed to calculate $c_{p}$ for given values of $\lambda$ and $\theta$ [1], [4], [5]. Here, the following approximation is used:

$$
c_{p}(\lambda, \theta)=0.73\left(\frac{151}{\lambda_{i}}-0.58 \theta-0.002 \theta^{2.14}-13.2\right) e^{-18.4 / \lambda_{i}}
$$

with

$$
\lambda_{i}=\frac{1}{\frac{1}{\lambda-0.02 \theta}-\frac{0.003}{\theta^{3}+1}} .
$$

It is not considered necessary to develop different approximations for the $c_{p}(\lambda, \theta)$ of various wind turbine types. The differences between the curves of wind turbine types are very small and can be neglected in dynamics simulations, although they are

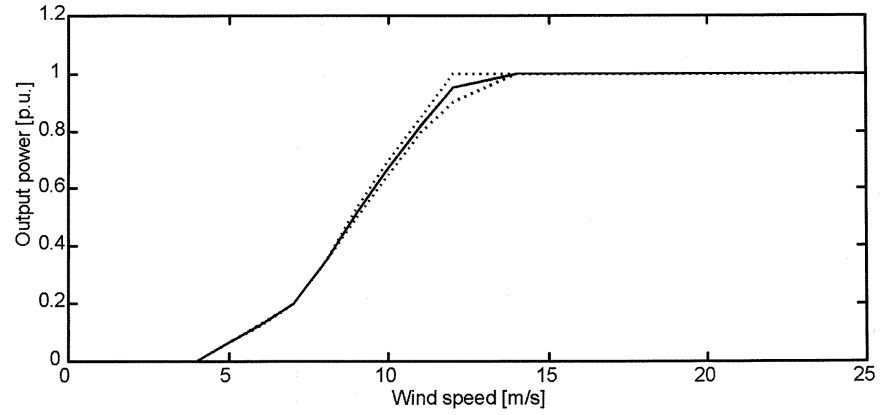

Fig. 2. Power curve of two commercial wind turbines (dotted) and numerical approximation (solid).

very important in other cases (e.g., when calculating the energy yield). In Fig. 2, the power curves of two commercial wind turbines are given, together with the general numerical approximation described by (4) and (5). The coefficients in (4) and (5) have been determined using a numerical optimization minimizing the error between the power curve following from the equations and the one from obtained from manufacturer documentation.

The rotor is modeled as a lumped mass and the shaft dynamics are neglected. It should be noted that this is only allowed when variable speed wind turbines are studied. In constant speed wind turbines, including a dynamic shaft model is very important, especially for flicker studies and transient stability investigations [11]. However, it has been shown experimentally that in variable speed wind turbines, the shaft properties are hardly reflected at the grid connection due to the decoupling effect of the power electronic converter [12], [13].

\section{Modeling of the Generator/Converter}

The combination of generator and converter is the main difference between the two most important actual variable speed wind turbine concepts. In the first concept, the decoupling of the grid frequency and the mechanical rotor frequency is implemented by using a doubly fed induction generator with a back-to-back voltage source converter feeding the rotor. In the second concept, it is implemented by fully decoupling the synchronous direct drive generator from the grid using a back-to-back voltage source converter or a combination of a diode rectifier coupled to the generator stator winding and a voltage source converter coupled to the grid. The synchronous generator can be excited using a rotor winding or permanent magnets [1].

The goal of the research presented in this paper is to develop a general model by which all variable speed wind turbine concepts can be represented. Although the way in which variable speed capability is realized differs among the various concepts, the differences in the behavior with respect to grid interaction are small. This can be explained by noticing that the power electronic converter decouples electrical and mechanical behavior of the wind turbine on the time frame that is of interest in power system dynamics studies. This conclusion is based on the following reasoning and supported by both theoretical and empirical evidence [14]-[17].

The voltage equations of both a doubly fed induction generator and a synchronous generator can be found in [2] and will not 
be reproduced here. First, the $d \psi / d t$ terms in the stator voltage equations of the doubly fed induction generator are neglected. This is routinely done in power system dynamics simulations for synchronous and asynchronous machines [2], [3].

Further, theoretical considerations and experiments lead to the conclusion that in both concepts, the current controllers on the power electronic converters act very fast. As a result, a new current reference value can be met within $10 \mathrm{~ms}$ or less. Ten milliseconds is the normal time step in power system dynamics simulations. Thus, it can be concluded that the current will reach its new value within one time step. This makes it possible to model the power electronics converter as a controlled current source instead of a controlled voltage source and to neglect the $d \psi / d t$ terms in the rotor voltage equations of the doubly fed induction generator and in the stator and rotor voltage equations of the direct drive synchronous generator.

These assumptions are only valid when

- the machine parameters are known;

- the controllers operate in their linear region;

- vector modulation is used;

- the terminal voltage approximately equals the nominal value.

The first two conditions have to be met by the wind turbine manufacturer and are assumed to be fulfilled here. The third assumption is met, because the control of the converter used in variable-speed wind turbines is nearly always based on vector modulation [1]. The last assumption is not met during grid faults. However, when a fault occurs, a variable speed wind turbine is quickly disconnected to protect the power electronic converter. Further, the response of the power electronic converter to a voltage drop is characterized by very-high-frequency phenomena that cannot be studied using normal power system dynamics simulation software. Therefore, a low-frequency representation of the behavior of the converter during faults must be incorporated in the model, such as is done for HVDC converters [18]. The appropriateness of this approach is beyond the scope of this paper.

As a result of the simplifications shown, an algebraic relation results between the $q$-component of the rotor current in the doubly fed induction generator and stator currents of the direct drive generator on one side and the electromechanical torque on the other. This means that generator torque set points can be reached instantaneously by injecting the appropriate rotor or stator currents. Therefore, it is not necessary to drag along the equations describing the two generator types. Instead, the generator can be modeled as a torque source, which immediately generates an amount of torque equal to the set point generated by the controller.

The only resulting differential equation associated with the generator and the converter that remains after this simplifications is the equation of motion

$$
\frac{d \omega_{m}}{d t}=\frac{1}{2 H}\left(T_{m}-T_{e}\right)
$$

In (6), $\omega$ is frequency [per unit]; $T$ is the torque [per unit]; and $H$ is the inertia constant of the rotating mass [s]. The indices $m$ and $e$ are mechanical and electrical, respectively. The value of

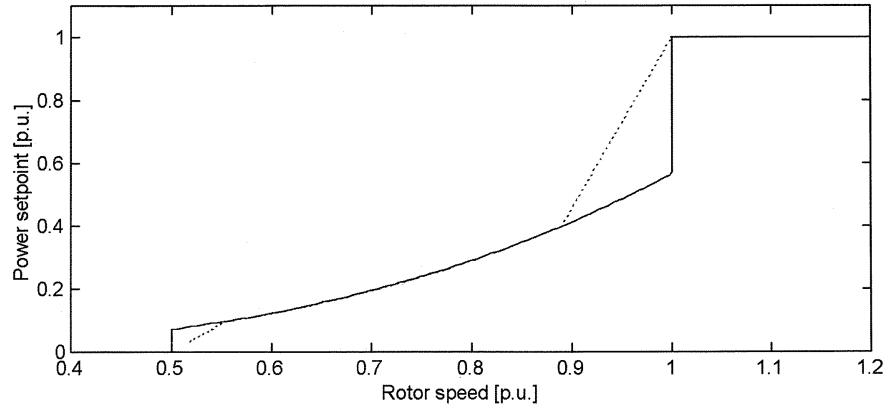

Fig. 3. Optimal (solid) and implemented (dotted) rotor speed versus power characteristic of an example variable-speed wind turbine.

$H$ is normally in the range of three to four and can be calculated from the moment of inertia of the rotating mass [2].

\section{E. Modeling of the Rotor Speed Controller}

The speed controller of the wind turbine model operates as follows:

- With a sample frequency $f_{s s}$ [hertz], the actual rotor speed is measured. From this value, a set point for generator real power is derived using the control characteristic. The value of $f_{s s}$ is in the order of $20 \mathrm{~Hz}$.

- From this value, a set point for the generated power is derived using the control characteristic.

- Taking into account the actual generator speed, a torque set point is derived from the power set point.

- As a result of the generator modeling approach described before, this torque set point is realized immediately.

To acquire a set point for generated real power, a rotor speed versus generator power characteristic is used. In most cases, the rotor speed is controlled in such a way that optimal energy capture is achieved. It is also possible to develop a rotor speed versus power characteristic that serves other goals, such as noise minimization.

The solid line in Fig. 3 depicts the rotor speed versus power characteristic that leads to optimal energy capture. At low wind speeds, the rotor speed is kept at its minimum by adjusting the generator torque. At medium wind speeds, the rotor speed varies proportional to the wind speed, and thus, with the cubic root of the power, according to (3). When the rotor speed reaches its maximum value, generator torque is kept at its maximum [19].

Controlling the power according to this speed versus power characteristic, however, causes some problems.

- The desired power is not uniquely defined at nominal and minimal rotor speed.

- If the rotor speed decreases from slightly above nominal speed to slightly below nominal speed or from slightly above minimal speed to slightly below minimal speed, the change in generated power is very large.

To solve these problems, a control characteristic similar to the one that leads to optimal energy capture is used here. This control characteristic is depicted by the dashed line in Fig. 3. The points at which the implemented control characteristic deviates from the control characteristic leading to optimal energy capture can be adjusted in the wind turbine model. If these points lie near the minimal and nominal rotor speed, the maximum amount of 
energy is extracted from the wind over a wide range of wind speeds, but rotor speed changes near the minimum and nominal rotor speed result in large power fluctuations. If these points lie further from the minimal and nominal rotor speed, the wind speed range in which energy capture is maximal is narrowed, but the power fluctuations near minimal and nominal rotor speed are smaller.

\section{F. Modeling of the Pitch Angle Controller}

The pitch angle controller is only active in high wind speeds. In those circumstances, the rotor speed can no longer be controlled by increasing the generated power, as this would lead to overloading the generator and/or the converter. To prevent the rotor speed from becoming too high, which would result in mechanical damage, the blade pitch angle is changed in order to reduce $c_{p}$.

Using (4) and (5), the pitch angle needed to limit the power extracted from the wind to the nominal power of the wind turbine can be calculated for each wind speed. From these equations, it can be concluded that the optimal pitch angle equals zero below the nominal wind speed and from the nominal wind speed on increases steadily with increasing wind speed. This observation greatly facilitates pitch control.

Furthermore, it should be taken into account that the pitch angle cannot change immediately, but only at a finite rate, which may be quite low due to the size of the rotor blades of modern wind turbines and the desire to save money on the blade drives. The maximum rate of change of the pitch angle is in the order from 3 to $10 \%$, depending on the size of the wind turbine. Further, because the blade pitch angle can only change slowly, the pitch angle controller works with a sample frequency $f_{p s}$, which is in the order of 1 to $3 \mathrm{~Hz}$. In Fig. 4, the pitch angle controller is depicted. The model offers the possibility to specify all parameters depicted in Fig. 4. In the simulations, the maximum rate of change of the pitch angle and $f_{p s}$ equal $3 \% \mathrm{~s}$ and $2 \mathrm{~Hz}$, respectively.

Note that using this controller type, the rotor speed is allowed to exceed its nominal value by up to $20 \%$, depending on $K_{p}$. However, a proportional controller is used, because

- a slight overspeeding of the rotor above its nominal value can be allowed and poses no problems for the wind turbine construction [19];

- the system is never in steady state due to the varying wind speed, so that the advantage of an integral controller, which can achieve zero steady state error, is not applicable.

\section{G. Modeling of the Voltage Controller}

The voltage controller is based on the notion that to increase the terminal voltage, more reactive power should be generated, and to decrease the terminal voltage, less reactive power should be generated by the wind turbine. As already stated before, variable-speed wind turbine concepts enable full reactive-power control, by changing the reactive component of the grid current. In the first concept, this done by changing the direct component of the rotor current and in the second concept by changing the reactive component of the converter current at the grid side. Although the reactive power is thus controlled in

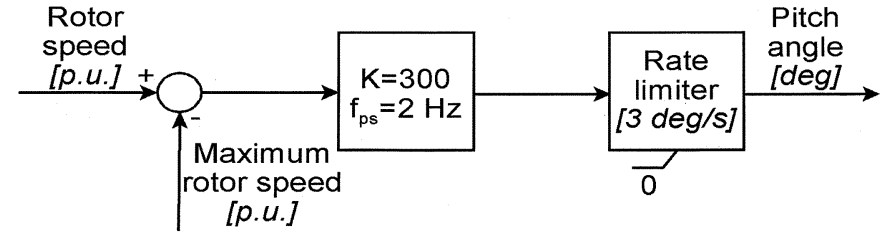

Fig. 4. Pitch angle controller model.

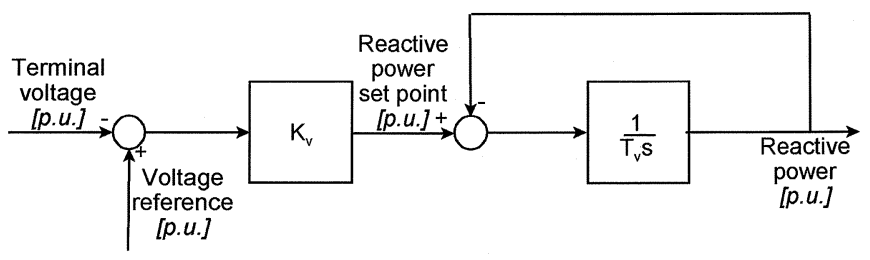

Fig. 5. Voltage controller model.

different ways, simulations have shown that the resulting grid interaction is very similar [20].

The voltage controller model used here is depicted in Fig. 5. The model offers the possibility to change all parameters. Note that the voltage controller can be used to operate the wind turbine at unity power factor by setting $K_{v}$ equal to 0 . In the simulations presented below, $K_{v}=50$ and $T_{v}=0.5 \mathrm{~s}$. The value for $T_{v}$ may seem quite high, but this can be explained by noticing that the voltage controller determines the reactive power. The current control loop, whose reference is derived from the reactive-power set point, reaches a set point very quickly as discussed before. Therefore, in the simulations, the reactive power is assumed to be the model's output instead of the current. The optimal value of $T_{v}$ is dependent on the grid characteristics.

\section{H. Modeling of the Protection System}

The protection system consists of three parts:

- a converter current limiter;

- a part that switches off the wind turbine when the terminal voltage deviates more than a specified amount from its nominal value during a specified time interval;

- a part that switches off the wind turbine when the grid frequency deviates more than a specified amount from its nominal value during a specified time interval.

The converter current must be limited to protect the semiconductor switches in the power electronic converter. For the same reason, the wind turbine must be switched off when the terminal voltage deviates more than a specified amount from its nominal value. Frequency changes are not a problem for the wind turbine itself. However, a large frequency deviation is an indicator that there exists some problem, islanding for example, which may make it desirable to disconnect the wind turbines or change the control strategy.

The converter current limiter boundaries are specified by giving the maximum amount of reactive power that the wind turbine can generate in per unit. From this value and the nominal active power, the nominal current is calculated for nominal terminal voltage. This way of specifying the current limits is considered more user friendly than specifying the current limits directly. It is also possible to specify an overloading percentage and a time during which the converter can be overloaded [21]. 
TABLE II

VALUES OF SOME MOdEl PARAMETERS FOR Wind TURBINES OF VARYING NOMINAl POWER When (4) AND (5) ARE USED to APPROXIMATE THE $c_{p}(\lambda, \theta)$ CURVE

\begin{tabular}{c|c|c|c}
\hline $\begin{array}{c}\text { Nominal } \\
\text { Power } \\
{[\mathbf{M W}]}\end{array}$ & $\begin{array}{c}\text { Rotor } \\
\text { Diameter } \\
{[\mathbf{m}]}\end{array}$ & $\begin{array}{c}\text { Minimum } \\
\text { Rotor Speed } \\
{[\mathbf{R P M}]}\end{array}$ & $\begin{array}{c}\text { Nominal } \\
\text { Rotor Speed } \\
{[\mathbf{R P M}]}\end{array}$ \\
\hline 0.75 & 46 & 15 & 30 \\
\hline 1.0 & 53 & 12.5 & 25 \\
\hline 1.25 & 60 & 11.5 & 23 \\
\hline 1.5 & 65 & 10.5 & 21 \\
\hline 1.75 & 70 & 9.5 & 19 \\
\hline 2.0 & 75 & 9 & 18 \\
\hline 2.5 & 84 & 8 & 16 \\
\hline
\end{tabular}

The parts of the protection system reacting to voltage and frequency are characterized by the upper and lower voltage and frequency boundary values that can be tolerated and by the time interval that these values are allowed to be exceeded. If voltage and frequency arrive within these boundary values after having exceeded them, the timer is reset and starts again if the boundary values are exceeded once more. All protection system parameters can be adjusted by the user.

\section{SimULATIONS}

\section{A. Parameter Sets for Wind Turbines of Various Ratings}

Many parameters that characterize a variable-speed wind turbine are linked. Examples of this are

- the $c_{p}(\lambda, \theta)$ curve, the nominal rotor speed, and the rotor diameter determine the nominal wind speed of a wind turbine of given nominal power;

- the allowable amount of rotor overspeeding determines the parameters in the pitch angle controller in Fig. 4;

- the minimum rotor speed determines the cut-in wind speed.

Due to these interdependencies, it is essential to use a consistent set of parameters when using the general wind turbine model presented before, because otherwise incorrect results may be obtained.

To allow the user of the general variable speed wind turbine model to easily model and simulate wind turbines of various sizes, in Table II, parameters for wind turbines of varying nominal power that can be used together with the numerical approximation of the $c_{p}(\lambda, \theta)$ given in (4) and (5) are given. Those parameters not given in this table can be set independently of the wind turbine size. Characteristic values of these parameters have been given above. If it is considered necessary to change the parameters in (4) and (5) in order to represent a specific wind turbine type, the data below may not be adequate and the data of the specific wind turbine being simulated should be used.

\section{B. Integration of the Wind Turbine Model in PSS/E}

The wind turbine model described before has been integrated into the power system dynamics simulation software package PSS/E from PTI using the FLECS language [18]. In dynamics simulation software, it is necessary to calculate the initial conditions of the system to be simulated from load-flow data before running the simulation. A solution to this problem is given in [6].

\section{Simulation Results}

After integration of the general variable-speed wind turbine model developed above in PSS/E, a case has been simulated using a 2-MW wind turbine with the speed versus power control characteristic of Fig. 3 and the parameter values given in Table II. The initial wind speed is below the nominal wind speed. After $5 \mathrm{~s}$, a wind speed ramp starts which leads to an increase in the average wind speed of $4 \mathrm{~m} / \mathrm{s}$ in $30 \mathrm{~s}$. After $10 \mathrm{~s}$, a wind speed gust with an amplitude of $-3 \mathrm{~m} / \mathrm{s}$ and a duration of $10 \mathrm{~s}$ occurs. The wind turbine is assumed to be erected in surroundings resembling a steppe, thus the roughness length $z_{0}$ is chosen equal to $1 \mathrm{e}-2 \mathrm{~m}$ according to Table $\mathrm{I}$.

The wind turbine is connected to an infinite bus. The impedance between the low-voltage terminals of the turbine and the infinite bus equals $0.011+0.11 j$ p.u. on a 2-MVA base. The time step equals $0.01 \mathrm{~s}$, the standard time step in PSS/E for a system frequency of $50 \mathrm{~Hz}$. Thus, the developed model meets the requirement that no smaller simulation time step is needed. In Fig. 6, the results are depicted. Starting from above, the wind speed, the rotor speed, the pitch angle, the active and reactive power, and the terminal voltage are depicted. First, the rotor speed increases with the wind speed. During the gust, the rotor acts as an energy buffer.

After $20 \mathrm{~s}$, the nominal power of the wind turbine is reached and the pitch angle controller becomes active to prevent rotor overspeeding. Note that the turbulence is for the largest part filtered out by the rotor inertia and is hardly reflected in the output power. The smoothness of the output-power fluctuations caused by wind gusts and turbulence that can be seen in these simulations is one of the important advantages that variablespeed wind turbines have above constant speed wind turbines [1].

From the lowest graph, it can be concluded that the voltage controller performs very well, because the terminal voltage is nearly equals 1.0 p.u., although wind speed and generated power change substantially during the simulated interval.

\section{Measurements}

In the upper graph of Fig. 7, two measured wind speed sequences are depicted. Then, the measured rotor speed, the pitch angle, and the measured output power of a variable-speed wind turbine with doubly fed induction generator (dotted) and with a direct drive synchronous generator (solid) is depicted. The measurements have been obtained from wind turbine manufacturers under a confidentiality agreement. Therefore, all values except wind speed and pitch angle are in per unit and their base values are not given.

The available measurements cannot be used for a qualitative validation of the model, because the wind speed is measured using a single anemometer, whereas the rotor has a large surface and because the measured wind speed is severely disturbed by the rotor wake, because the anemometer is located on the nacelle. Thus, although it would be possible to use the wind speed sequence measured by the anemometer as the model's input, it is not allowed to validate the model by comparing the measured and simulated response to this wind speed sequence quantitatively. Therefore, only a qualitative comparison is carried out. 

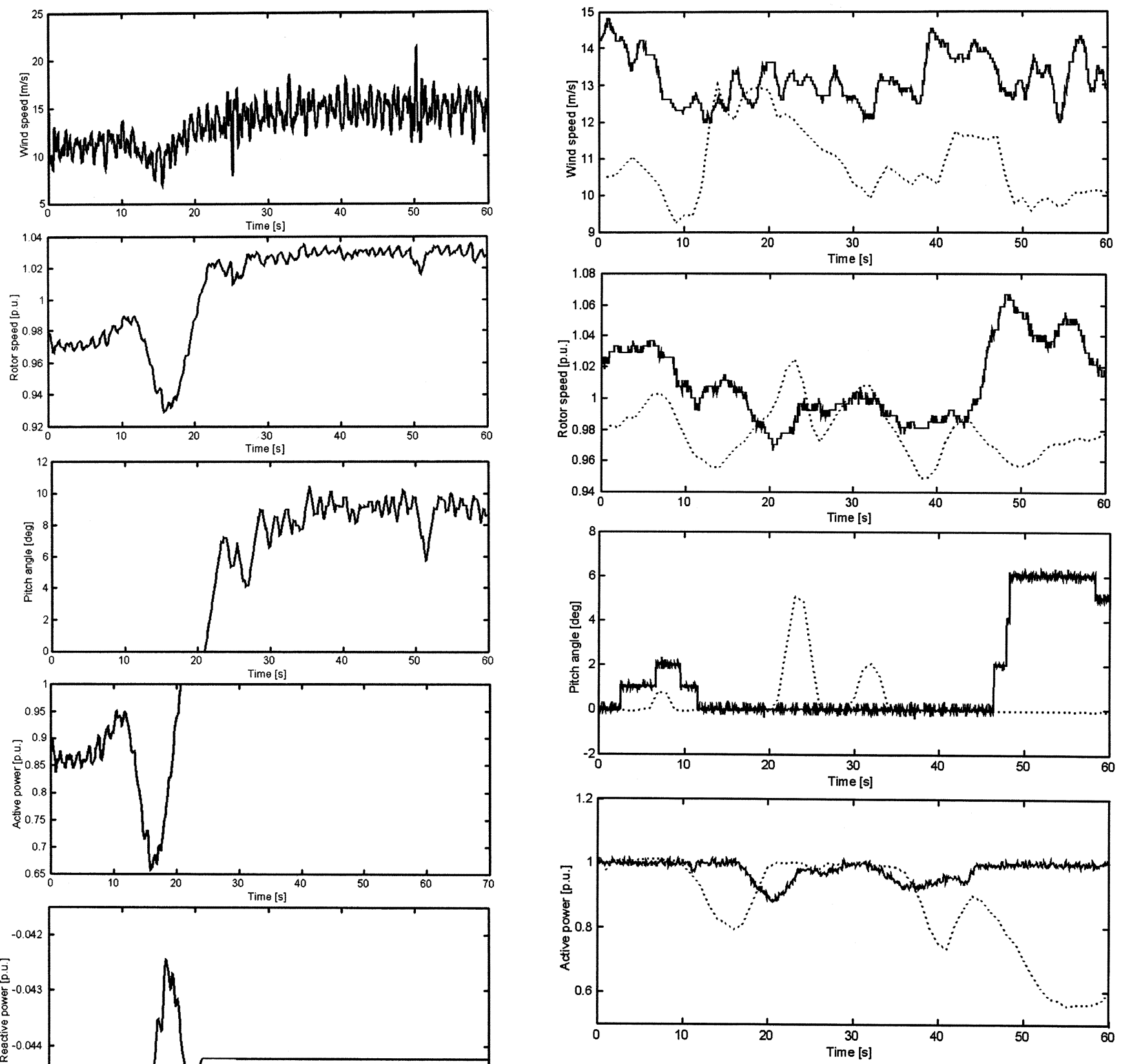

Fig. 7. Measured responses of two variable-speed wind turbines: doubly fed induction (dotted) and direct drive synchronous (solid). Starting from above: measured wind speed, rotor speed, pitch angle, and output power.

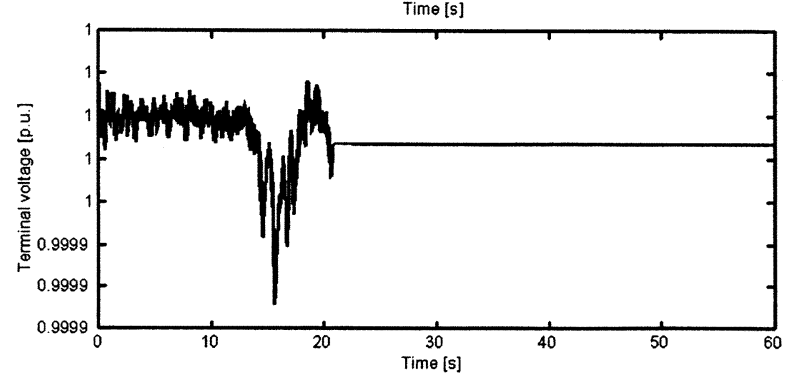

Fig. 6. Simulation results, starting from above: wind speed, rotor speed, pitch angle, active and reactive power, and voltage at the turbine's terminals.

When the simulated and measured responses are compared, it can be seen that

- the range of the measured and simulated output power fluctuations is similar;

- the range of the measured and simulated rotor speed fluctuations are similar;

- measured and simulated pitch angle behavior are similar. Although a quantitative validation of the model is not possible with the available measurements, this qualitative comparison gives at least some confidence in the accuracy and usability of the derived model and shows that the consequences of the assumptions and simplifications applied in modeling the rotor, the generator, and the controllers are limited.

\section{CONCLUSIONS}

In this paper, a general model for representing variable-speed wind turbines in power system dynamics simulation software 
was presented. Models of the subsystems of which a variable speed wind turbine consists were developed and practical values for the various parameters were given. It was concluded that both theoretical considerations and experimental evidence justify the representation of the two most important variable-speed wind turbine concepts with the same model in power system dynamics simulations.

The integration of the developed model into a power system dynamics simulation software package was discussed and simulation results that were obtained with the derived model were analyzed. When the response of the model to a measured wind speed sequence is compared with measurements, a sufficient degree of correspondence can be observed. This gives confidence in the presented model and shows that the consequences of the applied simplifications are limited.

\section{ACKNOWLEDGMENT}

The authors would like to thank Prof. dr. ir. G. A. M. van Kuik from the Wind Energy Institute of Delft UT for making available his experience. T. F. Laskowski from PTI, Schenectady, NY, is acknowledged for his valuable help in interfacing the wind turbine model with PSS/E.

\section{REFERENCES}

[1] S. Heier, Grid Integration of Wind Energy Conversion Systems. Chicester, U.K.: Wiley, 1998.

[2] P. Kundur, Power System Stability and Control. New York: McGrawHill, 1994.

[3] M. Ilić and J. Zaborsky, Dynamics and Control of Large Electric Power Systems. New York: Wiley, 2000.

[4] O. Wasynczuk, D. T. Man, and J. P. Sullivan, "Dynamic behavior of a class of wind turbine generators during random wind fluctuations," IEEE Trans. Power App. Syst., vol. 100, pp. 2837-2845, June 1981.

[5] P. M. Anderson and A. Bose, "Stability simulation of wind turbine systems," IEEE Trans. Power App. Syst., vol. 102, pp. 3791-3795, Dec. 1983.

[6] J. G. Slootweg, H. Polinder, and W. L. Kling, "Initialization of wind turbine models in power system dynamics simulations," in IEEE Porto Power Tech, Porto, Potugal, Sept. 10-13, 2001.

[7] "Loads and safety of wind turbine construction," The Danish Society of Engineers and the Federation of Engineers, Rep. Danish Std. DS 472, 1st ed., May 1992.

[8] M. Shinozuka and C.-M. Jan, "Digital simulation of random processes and its applications," J. Sound Vib., vol. 25, no. 1, pp. 111-128, 1972.

[9] H. A. Panofsky and J. A. Dutton, Atmospheric Turbulence, Models and Methods for Engineering Applications. New York: Wiley, 1984

[10] E. Simiu and R. H. Scanlan, Wind Effects on Structures, an Introduction to Wind Engineering, 2nd ed. New York: Wiley, 1986.

[11] V. Akhmatov, H. Knudsen, and A. H. Nielsen, "Advanced simulation of windmills in the electric power supply," Int. J. Elect. Power Energy Syst., vol. 22, no. 6, pp. 421-434, Aug. 2000.

[12] T. Petru and T. Thiringer, "Active flicker reduction from a sea-based 2.5MW wind park connected to a weak grid," in Nordic Workshop on Power and Industrial Electronics (NORpie'2000), Aalborg, Denmark, June 13-16, 2000

[13] T. Krüger and B. Andresen, "Vesta OptiSpeed-Advanced control strategy for variable speed wind turbines," in European Wind Energy Conf., Copenhagen, Denmark, July 2-6, 2001, pp. 983-986.

[14] R. Pena, J. C. Clare, and G. M. Asher, "Doubly fed induction generator using back-to-back PWM converters and its application to variable-speed wind-energy conversion," Proc. Inst. Elect. Eng., vol. 143, no. 3, pp. 231-241, May 1996.

[15] M. Fujimitsu, T. Komatsu, K. Koyanagi, K. Hu, and R. Yokoyama, "Modeling of doubly-fed adjustable-speed machine for analytical studies on long-term dynamics of power system," in Proc. PowerCon, Dec. 2000, pp. 25-30.
[16] D. C. Aliprantis, S. A. Papathanassiou, M. P. Papadopoulos, and A G. Kladas, "Modeling and control of a variable-speed wind turbine equipped with permanent magnet synchronous generator," in Int. Conf. on Elect. Mach., vol. 1, Aug. 2000, pp. 558-562.

[17] N. Hatziargyriou, Ed., CIGRE TF38.01.10, Paris, France, Nov. 2000.

[18] “On-line documentation PSS/E 25," Power Technologies, Inc., Schenectady, NY, Dec. 1997.

[19] E. Muljadi and C. P. Butterfield, "Pitch-controlled variable-speed wind turbine generation," IEEE Trans. Ind. Applicat., vol. 37, pp. 240-246, Jan./Feb. 2001

[20] J. G. Slootweg, S. W. H. de Haan, H. Polinder, and W. L. Kling, "Voltage control capabilities of various wind turbine concepts," in Proc. 2nd Int. Workshop on Transmission Networks for Offshore Wind Farms, Stockholm, Mar. 29-30, 2001.

[21] S. Arabi and P. Kundur, "Stability modeling of storage devices in FACTS applications," in 2001 IEEE Power Eng. Soc. Summer Meeting, Vancouver, B.C., Canada, July 15-19, 2001.

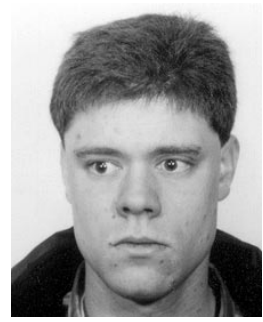

J. G. Slootweg (M'01) received the M.Sc. degree in electrical engineering from Delft University of Technology, Delft, The Netherlands, in 1998. He is currently pursuing the $\mathrm{Ph} . \mathrm{D}$. degree on large-scale integration of dispersed generation into existing electric grids at the Electrical Power Systems Laboratory of Delft University of Technology.

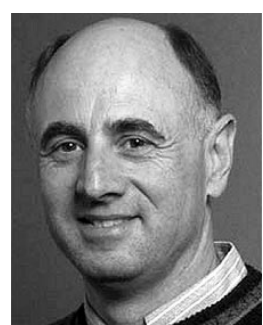

S. W. H. de Haan (M'99) received the M.Sc. degree in applied physics from the Delft University of Technology, The Netherlands, in 1975.

Currently, he is Associate Professor of Power Electronics at the Delft University of Technology, where he has been since 1995. His research interests include power quality conditioning (i.e., the development of power electronic systems for the conditioning of the power quality in the public electricity network).

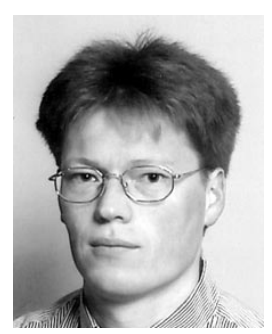

H. Polinder (M'97) received the M.Sc. and Ph.D. degrees in electrical engineering in 1992 and 1998, respectively, from the Delft University of Technology, The Netherlands.

Currently, he is an Assistant Professor at the Electrical Power Processing Laboratory at Delft University of Technology, Delft, The Netherlands, where he gives courses on electrical machines and drives. His main research interest is the field of generator systems in renewable energy, such as wind energy and wave energy.

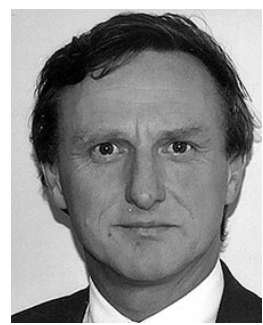

W. L. Kling (M'95) received the M.Sc. degree in electrical engineering from the Technical University of Eindhoven, Eindhoven, The Netherlands, in 1978.

Currently, he is a part-time professor at the Electric Power Systems Laboratory of Delft University of Technology, Delft, The Netherlands. He has experience in the area of planning and operation of power systems.

Mr. Kling is involved in scientific organizations such as Cigré and IEEE. He is the Dutch representative in the Cigré Study Committee 37 Planning and Development of Power Systems. 